\title{
REMARKS ON A FIXED-POINT THEOREM OF GERALD JUNGCK
}

\author{
MAIBAM RANJIT SINGH \\ Department of Mathematics \\ Manipur University \\ Impha1 - 795003, India \\ (Received August 18, 1988 and in revised form May 29, 1989)
}

\begin{abstract}
Jungck [1] obtained a fixed-point theorem for a pair of continuous selfmappings on a complete metric space. Recently, Barada K. Ray [2] extended the theorem of Jungck [1] for three self-mappings on a complete metric space. In the present paper we omit the continuity of the mapping used by Ray [2] and replace his four conditions by a single condition. Our results so obtained generalize and/or unify fixed-point theorems of Jungck [1], Ray [2], Rhoades [3], Ciric [4], Pal and Maiti [5], and Sharma and Yuel [6].
\end{abstract}

KEYWORDS AND PHRASES. Fixed Point Theorem, Continuous Self-Mappings, and Complete Metric Space.

1980 AMS SUBJECT CLASSIFICATION CODE. 54H25, $47 \mathrm{H} 10$.

\section{INTRODUCTION.}

We quote two theorems:

Theorem 1. (Jungck [1]). If $\mathrm{S}$ and $\mathrm{T}$ are continuous mappings of a complete metric space $(X, d)$ into itself such that

1) $S(X) \subset T(X)$,

11) $\mathrm{ST}=\mathrm{TS}$, and

iii) $d(S x, S y)<\alpha d(T x, T y)$ for every pair of points

$\mathrm{x}, \mathrm{y} \varepsilon \mathrm{X}$ and for $\alpha \varepsilon[0,1)$, then

$F_{S}=F_{T}=F_{S, T}=\{u\}$ for some $u$ in $X$,

where $\quad F_{S}=\{x \in X: X=S x\}, F_{T}=\{x \in X: x=T x\}$

and $\quad F_{S, T}=\{x \in X: X=S x=T x\}$.

Theorem 2 (Ray [2]). Let $T$ be a continuous mapping and $T_{1}$ and $T_{2}$ be any other two mappings of a complete metric space $(X, d)$ into itself such that

1) $\mathrm{TT}_{1}=\mathrm{T}_{1} \mathrm{~T}, 1=1,2$,

1i) $U_{i=1}^{2} T_{i}(X) \subseteq T(X)$, and

1i1) at least one of the following is satisfied for every pair of points $x, y$ in $X$ : 


$$
d\left(T_{1} x, T_{2} y\right)<\frac{\operatorname{ad}\left(T y, T_{2} y\right) d\left(T x, T_{1} x\right)}{1+d(T x, T y)}+\beta d(T x, T y),
$$

where $0<\alpha, \beta, \alpha+\beta<1$,

$$
\begin{gathered}
d\left(T_{1} x, T_{2} y\right)<\lambda \max \left\{d(T x, T y), 1 / 2\left[d\left(T x, T_{1} x\right)+d\left(T y, T_{2} y\right)\right],\right. \\
\left.1 / 2\left[d\left(T x, T_{2} y\right)+d\left(T y, T_{1} x\right)\right]\right\}
\end{gathered}
$$

where $0<\lambda<1$,

$$
\begin{array}{r}
d\left(T_{1} x, T_{2} y\right)<\mu \max \left\{d(T x, T y), d\left(T x, T_{1} y\right), d\left(T y, T_{2} y\right),\right. \\
\left.d\left(T x, T_{2} y\right), d\left(T y, T_{1} x\right)\right\}
\end{array}
$$

where $0<\mu<1 / 2$,

$$
\begin{array}{r}
d\left(T_{1} x, T_{2} y\right)<\max \left\{\left|K_{1} d(T x, T y)-K_{2} d\left(T x, T_{1} x\right)\right|,\right. \\
\left.\left.\mid K_{1} d(T x, T y)-K_{2} d\left(T y, T T_{2} y\right)\right\}\right\}
\end{array}
$$

where $-1<k_{2}<k_{1}<k_{2}+1<2, k_{1}<1$.

Then $\mathrm{F}_{\mathrm{T}}, \mathrm{T}_{1}, \mathrm{~T}_{2}$ is non-empty, where

$$
\mathrm{F}_{\mathrm{T}, \mathrm{T}_{1}, \mathrm{~T}_{2}}=\left\{\begin{array}{lll}
\mathrm{x} & \varepsilon & \mathrm{X}: \mathrm{x}=\mathrm{Tx}=\mathrm{T}_{1} \mathrm{x}=\mathrm{T}_{2} \mathrm{x}
\end{array}\right\}
$$

Furthermore, $F_{T_{1}}=F_{T_{2}}=F_{T, T_{1} T_{2}}=\{u\}$, for some $u$ in $X$.

2. MAIN RESULTS.

Now we give our result.

THEOREM 2.1. Let $(X, d)$ be a complete metric space. Let $T, T_{1}, T_{2}: X+X$ satisfy (1), (ii) of Theorem 2 and (i) let the following conditions hold for every palr of points $x, y$ in $x$ :

$$
\begin{aligned}
d\left(T_{1} T x, T_{2} T y\right)<\mu & \max \left\{d\left(x, T_{1} T x\right), d\left(y, T_{2} T y\right), d\left(y, T_{1} T x\right), d\left(x, T_{2} T y\right),\right. \\
& {\left[d\left(x, T_{1} T x\right)+d\left(y, T_{2} T y\right)\right],\left[\frac{\alpha\left[1+d\left(y, T_{2} T y\right)\right] d\left(x, T_{1} T x\right)}{1+d(x, y)}\right.} \\
& +B\left[d\left(x, T_{1} T x\right)+d\left(y, T_{2} T y\right)\right]+v\left[d\left(y, T_{1} T x\right)+d\left(x, T_{2} T y\right)\right] \\
& +\delta d(x, y)],\left|k_{1} d(x, y)-K_{2} d\left(x, T_{1} T x\right)\right|, \\
& \left.\left|k_{1} d(x, y)-k_{2} d\left(y, T_{2} T y\right)\right|\right\}
\end{aligned}
$$


where $\quad 0<\mu<1, \alpha, \beta, \nu, \delta>0, \alpha+\beta+\nu+\delta<1,2 \nu+\delta<1$, $0<\frac{\mu\left(\beta+\frac{\nu}{1-\mu}+\delta\right)}{\left.\alpha+\frac{\delta}{\beta}+\nu\right)}<1,-1<\mathrm{K}_{2}<\mathrm{K}_{1}<1+\mu \mathrm{K}_{2}<2, \mathrm{~K}_{1}<1$.

Then $\mathrm{F}_{\mathrm{T}, \mathrm{T}_{1} \mathrm{~T}_{2}}$ is non-empty, where

$$
\mathrm{F}_{\mathrm{T}_{,} \mathrm{T}_{1}, \mathrm{~T}_{2}}=\left\{\mathrm{x} \in \mathrm{X}: \mathrm{x}=\mathrm{Tx}=\mathrm{T}_{1} \mathrm{x}=\mathrm{T}_{2} \mathrm{x}\right\}
$$

Furthermore, $\mathrm{F}_{\mathrm{T}_{1}}=\mathrm{F}_{\mathrm{T}_{2}}=\mathrm{F}_{\mathrm{T}, \mathrm{T}_{1}, \mathrm{~T}_{2}}=\{\mathrm{u}\}$, for some $\mathrm{u}$ in $\mathrm{X}$.

PROOF. Let $x_{0} \varepsilon x$, define

$$
\begin{aligned}
& x_{2 n+1}=T_{1} x_{2 n}, n=0,1,2 \ldots \\
& x_{2 n}=T_{2} x_{2 n-1}, n=1,2,3 \ldots
\end{aligned}
$$

Then, using Theorem 2.1, (1), we have

$$
d\left(x_{2 n+1}, x_{2 n}\right)<K d\left(x_{2 n}, x_{2 n-1}\right)
$$

where $K=\max \left\{\mu, \frac{\mu}{1-\mu}, \frac{\mu(\beta+\nu+\delta)}{1-\mu(\alpha+\beta+\nu)}, r\right\}$

$$
\text { where } r=\begin{aligned}
& \mu \max \left\{\mathrm{K}_{1}-\mathrm{K}_{2}, \frac{\mathrm{K}_{1}}{1+\mu \mathrm{K}_{2}}\right\}, \mathrm{K}_{1}>0, \\
& \mu \max \left\{\mathrm{K}_{1}-\mathrm{K}_{2}, \frac{-\mathrm{K}_{1}}{1-\frac{1}{\mu}} \mathrm{K}_{2}\right\}, \mathrm{K}_{1}<0 .
\end{aligned}
$$

$\therefore\left\{x_{n}\right\}$ is a Cauchy sequence. Since $X$ is complete there exists u $\varepsilon \times$ such that $x_{n}+u$ as $n \rightarrow \infty$.

Now,

$$
d\left(T_{1} T u, x_{2 n}\right)=d\left(T_{1} T u, T T_{2 n-1}\right) \text {. }
$$

Then using Theorem 2.1 (i) and allowing $n+\infty$ such that $x_{2 n}+u, x_{2 n-1}+u$ etc, we have $u=T_{1} T u$. Hence $u=T_{1} T u=T_{1} u$ using Theorem 2 (1). Further, $d\left(x_{2 n+1}, T_{2} T u\right)=d\left(T_{1} T x_{2 n}, T_{2} T u\right)$. Again using Theorem $2(1)$ and allowing $n \rightarrow \infty$ such that $x_{2 n}+u, x_{2 n+1}+u$ etc, we have $u=T_{2} T u$. Hence $u=T_{2} T u=T T_{2} u$. Now, let $v$ denote any common fixed point of $T_{1} T$ and $T_{2} T$. From Theorem 2.1 (i), it is easy to see that $u=v$ since $2 v+\delta<1$. For proving $u=$ Tu we have

$$
d(T u, u)=d\left(T T_{1} T u, T_{2} T u\right)=d\left(T_{1} T T u, T 2 T u\right)
$$

which yields $\mathrm{Tu}=\mathrm{u}$ using Theorem 2.1 (1). Hence $\mathrm{u}=\mathrm{T}_{1} \mathrm{Tu}=\mathrm{T}_{1} \mathrm{u}$. Similarly, $\mathrm{u}=\mathrm{T}_{2} \mathrm{Tu}$ $=T_{2} u$. Hence, $u=T u=T_{1} u=T_{2} u$ which shows that $F_{T}, F_{T_{1}}, F_{T_{2}}$ are non-empty. Then we 
can see that $F_{T_{1}}=F_{T_{2}}=F_{T, T} T_{2}=\{u\}$ for some $u$ in $X$. This completes the proof. EXAMPLE. Let $X=[0,1]$ with Euclidean metric d. Let $T x=x, 0<x<1, T x=1 / 2$, $x=1, T_{1} x=\frac{x}{4}, 0<x<1, T_{1} x=\frac{1}{8}, x=1, T_{2} x=\frac{x}{8}, 0<x<1, T_{2} x=\frac{1}{16}, x=1$. Here $T, T_{1}, T_{2}$, are all discountinuous at $x=1$ and have a unique common $f i x e d$ point $x=$ 0. Take $x=\frac{1}{2}, y=\frac{1}{4}$. Obviously all the conditions (i), (11) of Theorem 2 and (i) of Theorem 2.1 hold true. Hence the result.

REMARKS. (1) Contractive Definition 20 of Rhoades [3] is a special case of condition (1) of Theorem 2.1. (2) Theorem 1 of Circi [4], Theorem 1 of Pal and Mait [5], and Theorem 4 of Sharma and Yuel [6] are speclal cases of Theorem 2.1.

ACKNOWLEdement. My sincere thanks are due to Professor A.K. Chatterjee for his guidance in the presentation of this paper and also to the anonymous referee for his valuable comments in the improvement of the same.

\section{REFERENCES}

1. JUNGCK, G., Commuting Mappings and Fixed Points, Amer. Math. Monthly 83 (1976), 261-263.

2. RAY, B.K., Remarks on a Fixed-point Theorem of Gerald Jungck, Jour. Univ. Kuwalt (Science) 12(2) (1985), 169-171.

3. RHOADES, B.E., A Comparison of Various Definitions of Contractive Mappings Trans. Amer. Math. Soc. 226 (1977), 257-290.

4. Ciric, L.B., A Generalization of Banach's Contraction Principle, Proc. Amer. Math. Soc. $45(1974), 267-273$.

5. PAL, T.K. and MAITI, M., Extension of Fixed-point Theorems of Rhoades and Ciric, Proc. Amer. Math. Soc. 64 (1977), 283-286.

6. Sharma, P.L. and YUEL, A.K., A Unique Fixed Point Theorem in Metric Space, Bull. Cal. Math. Soc. $76(1984), 153-156$. 




Advances in

Operations Research



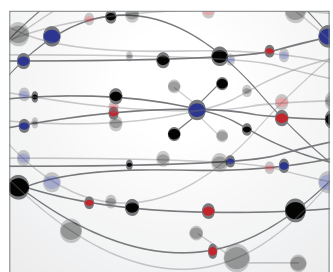

\section{The Scientific} World Journal
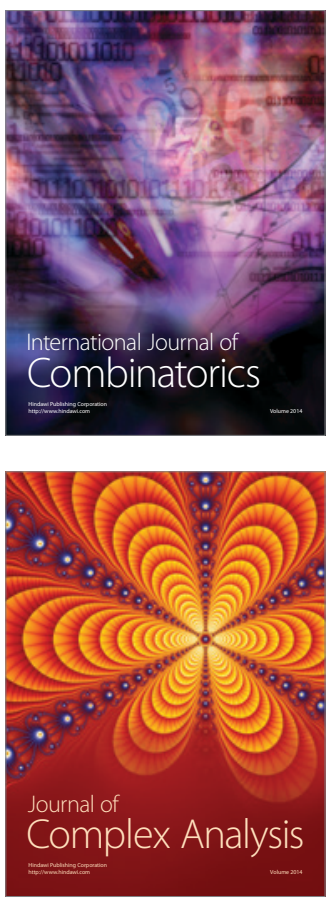

International Journal of

Mathematics and

Mathematical

Sciences
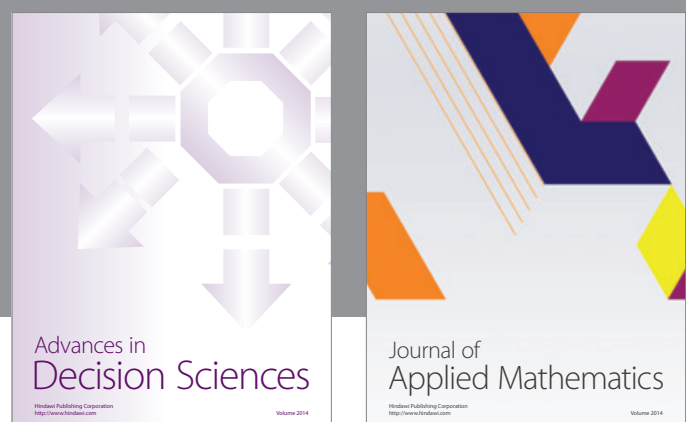

Journal of

Applied Mathematics
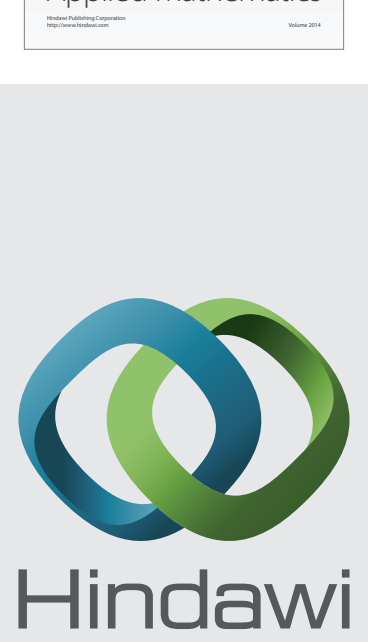

Submit your manuscripts at http://www.hindawi.com
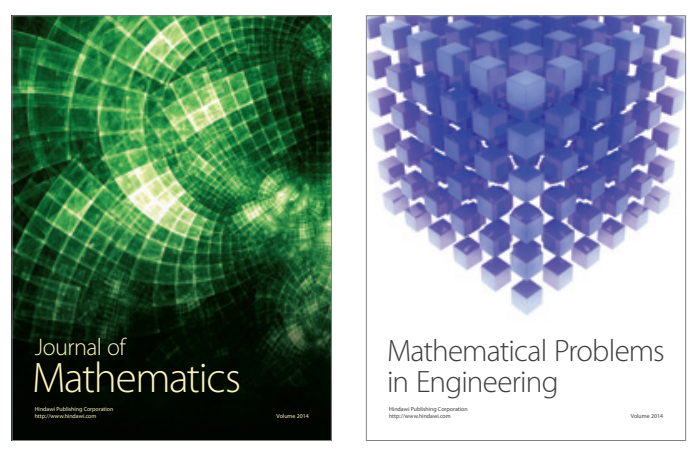

Mathematical Problems in Engineering
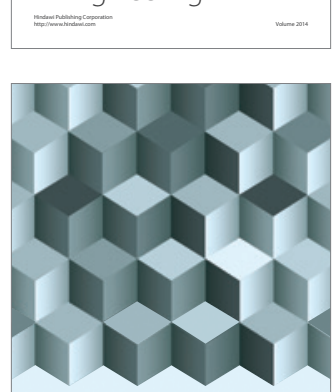

Journal of

Function Spaces
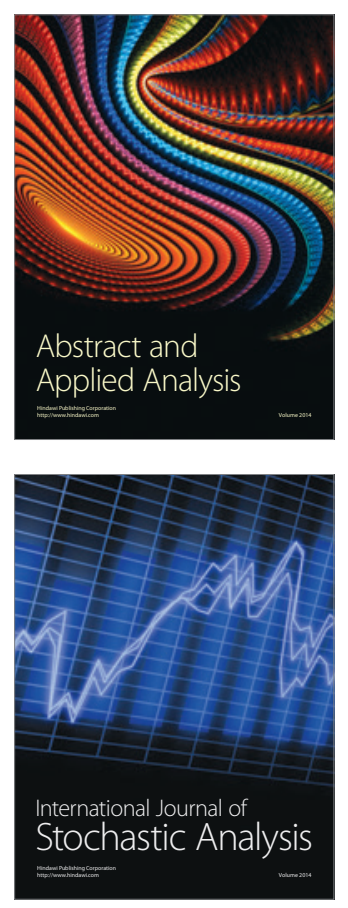

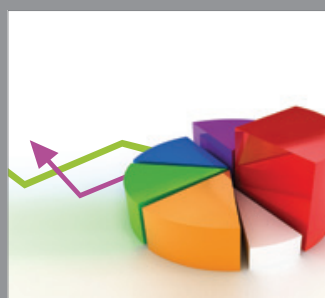

ournal of

Probability and Statistics

Promensencen
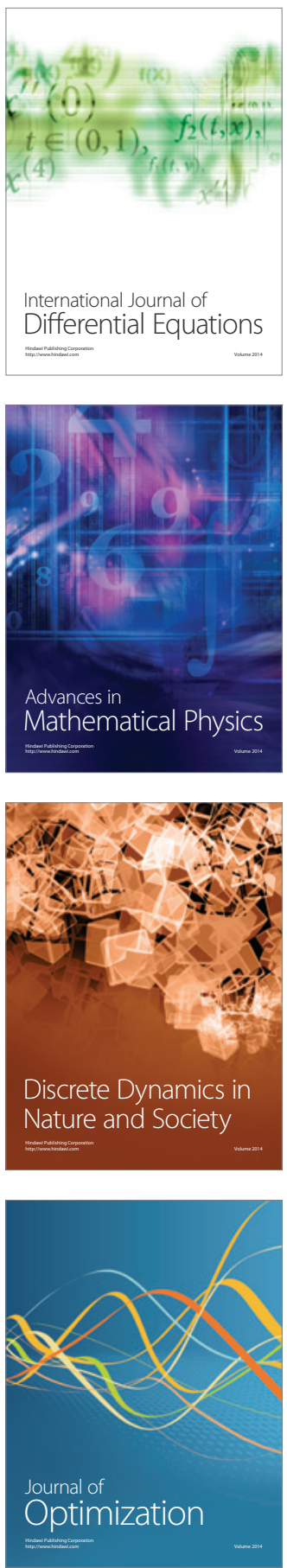